\title{
Effect of water deficits on the growth and secondary metabolites of Salvia dolomitica Codd. and Salvia namaensis Schinz
}

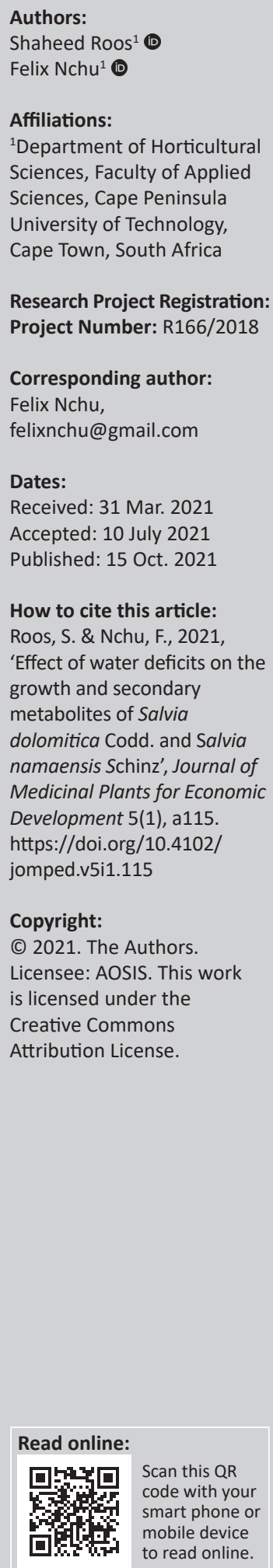

Background: Salvia dolomitica Codd. and Salvia namaensis Schinz. are indigenous to southern Africa and are used as medicinal plants in folk medicine.

Aim: This study aimed to assess the effects of different levels of water deficit treatments on the growth, concentration of secondary metabolites, and anti-Fusarium oxysporum activity of S. dolomitica and S. namaensis.

Setting: Experiments were carried out on the Bellville campus of the Cape Peninsula University of Technology, Cape Town.

Methods: Four weeks old seedlings of the two species were subjected to 3-, 6-, 9- and 12-day water deficit regimes. Secondary metabolites such as polyphenols, alkaloids, and flavanols were assessed using spectroscopic methods. The anti-fungal activities of crude extracts obtained from plants were evaluated in a micro-dilution bioassay.

Results: In all treatments, the plant height, crown width, number of stems and leaves, and fresh and dry weights reduced with increased water deficits. Acetone extracts from all treatments showed anti-fungal activity. However, extracts from the treatment with moderate water deficit (6-day watering interval) recorded significantly $(P<0.01)$ better inhibition of $F$. oxysporum at the $18 \mathrm{~h}$ post incubation than the commercial fungicide, Mancozeb.

Conclusion: This research has revealed that mild to moderate water deficit level favours the accumulation of alkaloids in S. dolomitica. Meanwhile, mild to severe water deficit significantly lowered flavanol content in S. namaensis. There was a correlation between the increase in total alkaloid contents and the enhanced anti-fungal activity of extracts of S. dolomitica. The present findings pave the way for optimised cultivation of medicinal plants and development of bioactive natural products.

Keywords: polyphenols; alkaloids; flavanols; Fusarium oxysporum; water deficit; Salvia species.

\section{Introduction}

South Africa is ranked as the 30th driest country globally (World Resources Institute 2015). According to the World Economic Forum (2017), the third-highest risk for doing business in South Africa is its crisis with access to fresh water. Droughts are expected to become more frequent and intense as global temperates increases (W.W.F.-SA 2016). Even though South Africa is already using too much water, it is forecasted that more water will be needed in the agricultural, industrial, and municipal sectors, in the future (Donnenfeld, Crookes \& Hedden 2018).

Although South Africa is a water-scarce country (Goldin 2010; Muller et al. 2009), it is home to 6\% of the world's plant diversity (Raimondo 2015), and has one of the richest temperate flora globally (Staden \& Lotter 2015). South Africa has many indigenous medicinal species that have the prospects of becoming sources of natural pesticides. The global demand for natural products is increasing as the world becomes more conscious of synthetic products' negative impacts on human and environmental health (Saha, Dasgupta \& Saha 2005).

In India, scientists in collaboration with the International Crops Research Institute for the Semi-Arid Tropics (ICRISAT) and local Indian farming communities, selected drought-resistant medicinal plants that the farmers can intercrop with the food crops that are commonly cultivated. The intention was for farmers to generate more income. Furthermore, farmers who had started growing medicinal plants had doubled or even tripled their incomes (Antonucci 2016). In 2016, India's prime minister 
initiated a project called the 'Aroma Mission', which promotes the cultivation of marketable medicinal and aromatic crops in unproductive areas, including those affected by water scarcity, drought, salinity, or floods (Srivastava 2016). There are also several similar initiatives in South Africa, supported by provincial governments and municipalities (Van Wyk \& Prinsloo 2018).

Efforts to optimise the yield of medicinal plant materials through cultivation methods or techniques have been receiving much attention lately as a result of the rise of multidrug-resistant organisms (MDROs) (Chen et al. 2016; Isah 2019). The success rate of developing a new drug from natural medicinal origins is higher compared to synthetic drugs, with the latter being very expensive and difficult to develop (Pan et al. 2013). Manipulation of the ambient environmental factors has been used to successfully enhance secondary metabolite production by plants (Ramakrishna \& Ravishankar 2011). Many studies have revealed that medicinal plants grown under certain water deficit conditions resulted in significantly higher concentrations of relevant secondary metabolites than their unstressed counterparts (Kleinwächter \& Selmar 2015). Metabolic reactions triggered by drought stress are responsible for the higher natural product accumulation in plants grown in semi-arid regions (Al-Gabbiesh, Kleinwächter \& Selmar 2014).

Different environmental stresses cause plants to produce various secondary metabolites that help them adapt to those stresses (Berini et al. 2018; Kroymann 2011). The production of secondary metabolites by plants can be elicited by changing the ambient biotic and abiotic factors (Caretto et al. 2015; Narayani \& Srivastava 2018; Rejeb, Pastor \& MauchMani 2014). Moreover, the presence of secondary metabolites that are affected under water shortage can impact the commercial medicinal value of plants (Tátrai et al. 2016). Plant secondary metabolites can be divided into three major groups, namely, terpenoids; nitrogen-containing alkaloids and sulphur-containing compounds and flavonoids; and allied phenolic and polyphenolic compounds. These secondary metabolites act as defence molecules against microbes, viruses, or other competing plants (Pusztahelyi, Holb \& Pócsi 2015; Wink 2003). Antimicrobial compounds restrict pathogens' growth by activating specific signalling pathways leading to $\mathrm{Ca}^{2+}$ elevation and reactive oxygen species (ROS) burst by binding to cell membranes followed by leakage of cell components of pathogenic fungi such as Fusarium oxyporum (Ito et al. 2007).

Drought often causes oxidative stress, thereby affecting the amounts of flavonoids and phenolic acids in plant tissues (Larson 1998). Water stress can increase the tannin and saponin contents of plants (Umebese \& Falana 2013), which are reported to have anti-fungal properties (Arif et al. 2009). Under drought stress, the closing of the stomata results in a series of consequent physiological and/or biochemical adjustments aimed at balancing the photosynthetic process as well as at enhancing the plant defence barriers against the drought-promoted stress. These barriers include the stimulation of antioxidant systems, stimulation of aquaporin synthesis and the accumulation of osmolytes, which are some of the mechanisms used by plants to overcome the unfavourable period of water deficit (Kapoor et al. 2020). In the current context, it is plausible to think that water-stressing indigenous Salvia plants during cultivation could enhance the production of secondary metabolites, thereby increasing the plant extracts' bioactivity against F. oxysporum.

Salvia dolomitica Codd, commonly known as dolomite sage or pilgrim's rest pink sage, is a fast-growing shrub and is restricted to the provinces of Limpopo and Mpumalanga, where it grows on dolomite rock outcrops at altitudes of $1150 \mathrm{~m}-1900 \mathrm{~m}$ (Clebsch 2003; McQuillan 2013). The major compounds in S. dolomitica are: $\alpha$-pinene $(7.1 \%), \delta$-3 carene $(7.5 \%)$, limonene (9.7\%), 1.8-cineole (17.6\%), $\beta$-caryophyllene (17.4\%), and borneol (8.5\%). The methanol:chloroform (1:1) extracts of $S$. dolomitica contain: Betulafolientriol oxide, Caffeic acid, Oleanolic/ursolic acid, and Rosmarinic acid (Kamatou et al. 2008).

Salvia namaensis Schinz, commonly known as Nama sage, is a well branched, semi-woody perennial shrub that is fast growing. The species comes from Namaqualand, Namibia or the Northern Cape as indicated by the epithet namaensis. It grows at $400 \mathrm{~m}-1700 \mathrm{~m}$ in well-drained, rocky, or sandy soil on limestone and dolerite hills (Clebsch 2003; McQuillan 2011). The methanol:chloroform (1:1) extracts of $S$. namaensis contain: 7-O-Methylepirosmanol, Betulafolientriol oxide, Caffeic acid, Carnosol, Carnosic acid, Oleanolic/ursolic acid, and Rosmarinic acid (Kamatou et al. 2008).

This research aimed to determine the effect of water deficits on the phenolic compounds of the aerial parts of two indigenous South African Salvia species, namely Salvia dolomitica and Salvia namaensis.

\section{Materials and methods Research design}

Rooted cuttings of two Salvia species, S. dolomitica and S. namaensis, were randomly exposed to four watering regimes in a greenhouse experiment with controlledenvironmental conditions. The plants were arranged in a randomised complete block design on a cement floor inside the research greenhouse where the plants were exposed to natural sunlight that entered through the polycarbonate roof. At the end of the experiment, data on different plant growth parameters, secondary metabolite contents and antifungal activity were collected.

\section{Propagation of Salvia dolomitica and Salvia namaensis cuttings}

Semi-hardwood cutting materials from indigenous S. dolomitica and S. namaensis were obtained from the Kirstenbosch National Botanical Garden, Cape Town, courtesy of the curator at the time, the late Mr Philip le Roux. One hundred, $10 \mathrm{~cm}$ cuttings, of each species were propagated in 128-cell, styrofoam trays 
containing equal volumes of river sand and perlite. These substrate materials were pre-sterilised with Captab WP (4 g in 1 L), supplied by Villa Crop Protection, Kempton Park, South Africa, before use. The trays of cuttings were placed on hotbeds maintained at a temperature of $26.5^{\circ} \mathrm{C}$ under intermittent mist in the production glasshouse with controlled environmental conditions $\left(22^{\circ} \mathrm{C} ; 100 \% \mathrm{RH}\right)$ until the roots appeared through the drainage holes of the trays.

\section{Greenhouse experiment}

The experiment was conducted in a research greenhouse on the Bellville campus of the Cape Peninsula University of Technology (CPUT) in Cape Town. Four-week-old, rooted cuttings of S. dolomitica and S. namaensis were individually transplanted into $15 \mathrm{~cm}$ brown plastic pots filled with sterilised medium containing equal parts of 1:1:1 silica sand, coir, and perlite. Sixty-four, 4-week old, potted cuttings of each of the two Salvia species were used in the water deficit experiment. The two groups of plants were divided into four treatments of 16 replicates each. A preliminary trial had shown that watering the plants with $250 \mathrm{~mL}$ of reverse osmosis (RO) water, every 3 days, was sufficient to prevent wilting, and thus, this watering regime was used as treatment one (T1 - no water deficit). In treatment 2 (T2 - mild deficits), 16 plants of each species were irrigated with $250 \mathrm{~mL}$ of water every 6 days. In treatment 3 (T3 - moderate), 16 plants of each of the two species were watered every 9 days, and plants in the fourth treatment (T4 - severe) were watered every 12 days. The experiment was conducted for 11 weeks and the plants were irrigated with $\mathrm{RO}$ water according to the irrigation regimes per treatment.

The potted plants were placed on the cement floor inside the research greenhouse, where the plants were exposed to natural sunlight that entered through the polycarbonate roof. The experiment followed a complete randomised block design. Temperatures inside were maintained between $24^{\circ} \mathrm{C}$ and $26^{\circ} \mathrm{C}$ during the day and $15^{\circ} \mathrm{C}-20^{\circ} \mathrm{C}$ during night, and Relative humidity $(\mathrm{RH})$ was maintained at $74 \%$. The plants' height was measured at the beginning and the end of the experiment using a measuring tape from the surface of the medium inside the plant pot to the tip of the tallest shoot. The crown width for each plant was measured from the tips of the two shoots that grew furthest from each other on a horizontal plane.

The biomass for each of the replicates was calculated postharvest. Individual plants were harvested at the end of the experiment by cutting the stems at the base level to the growth medium's surface. The plants were weighed, and their fresh weight was recorded. After being dried in a thermo-oven at $40{ }^{\circ} \mathrm{C}$ for 7 days in individual brown labelled paper bags, dry weights were recorded.

\section{In vitro fungal screening using micro-dilution assay}

As described by Ntobela et al. (2020), the micro-dilution method was employed to determine the minimum inhibitory concentration (MIC) for the extracts. Five grams of milled material of five replicates per treatment of $S$. dolomitica and $S$. namensis was extracted with $25 \mathrm{~mL}$ acetone and evaporated under a fan. The extracts were diluted into acetone to obtain a starting concentration of $6 \mathrm{mg} / \mathrm{mL}$. The starting concentration was diluted two-fold in each successive serial dilution. The strain of Fusarium oxysporum glycines strain (UPFC no. 21) that was used in this bioassay was obtained from existing cultures in the Department of Horticultural Sciences, CPUT, and was sub-cultured from stock agar plates and transferred into Nutrient Broth (Merck, South Africa) for $4 \mathrm{~h}$. The fungal cultures $(100 \mu \mathrm{L})$ were added to each well of the 96 -well microplates $\left(10^{5}\right.$ cells $/ \mathrm{mL}$ ). Mancozeb (Stodels Pty Ltd. Garden Centre, Cape Town, South Africa) served as the positive control. Forty microliters $(40 \mu \mathrm{L})$ of $0.2 \mathrm{mg} / \mathrm{mL}$ of p-iodonitrotetrazolium chloride (INT) (Sigma) dissolved in sterile distilled water was added to each microplate well, sealed in a plastic bag and incubated at $37^{\circ} \mathrm{C}$ and $100 \% \mathrm{RH}$. The INT will show pink colour in presence of fungal growth. The MIC values were recorded at the 6th, 12th, 18th, and 24th hour of incubation of the microtiter plates. Minimum inhibitory concentration values were recorded after comparing the pink colour of the wells to known concentration markers for individual rows of the microtiter plates using visual observations. The anti-fungal bioassay (MIC) consisted of three replicates per treatment.

\section{Determination of polyphenol, flavanol and alkaloid contents}

Total alkaloid content in the plant extracts was determined using the spectroscopic method described by Fadhil et al. (2007). Briefly, the supernatants of aqueous extracts that were obtained by extracting $100 \mathrm{mg}$ of the ground aerial plant samples with $10 \mathrm{~mL}$ of aqueous ethanol for $2 \mathrm{~h}$ followed by centrifuging at $4000 \times \mathrm{g}$ for $10 \mathrm{~min}$ were used in the assay. The extract supernatant $(2 \mathrm{~mL})$ and atropine standard solutions were mixed with sodium phosphate buffer $(5 \mathrm{~mL})$ and bromocresol green solution $(12 \mathrm{~mL})$. Subsequently, we added $12 \mathrm{~mL}$ of chloroform to the solution, and the solution was mixed vigorously using a vortex mixer (Espinoza et al. 2019). The absorbance at $417 \mathrm{~nm}$ was determined, and the concentration of $\mathrm{mg}$ atropine equivalent per $\mathrm{g}$ dry weight ( $\mathrm{mg}$ $\mathrm{AE} / \mathrm{g} \mathrm{DW}$ ) in the sample using a standard curve of atropine was calculated. The total polyphenol content of the aqueous ethanol extracts of dried S. dolomitica and S. namaensis materials were determined by the Folin-Ciocalteu method (Singleton, Orthofer \& Lamuela-Raventos 1999). Briefly, $25 \mu \mathrm{L}$ of the aqueous extracts was mixed with $125 \mu \mathrm{L}$ Folin-Ciocalteu reagent (Merck, South Africa) and diluted 1:10 with distilled water in a 96-well microplate. After $5 \mathrm{~min}, 100 \mu \mathrm{L}(7.5 \%)$ aqueous $\mathrm{Na}_{2} \mathrm{CO}_{3}$ (Sigma-Aldrich, South Africa) was added to the well. The plates were incubated at room temperature for $2 \mathrm{~h}$ before the absorbance was read at $765 \mathrm{~nm}$ using a Multiskan plate reader (Thermo Electron Corporation, USA). The standard curve was prepared using $0 \mathrm{mg} / \mathrm{L}, 20 \mathrm{mg} / \mathrm{L}$, $50 \mathrm{mg} / \mathrm{L}, 100 \mathrm{mg} / \mathrm{L}, 250 \mathrm{mg} / \mathrm{L}$ and $500 \mathrm{mg} / \mathrm{L}$ gallic acid in $10 \%$ ethanol (Singleton et al. 1999), and the results were expressed as mg gallic acid equivalents per $\mathrm{g}$ dry weight (mg GAE/g DW) (Espinoza et al. 2019). The total flavanol content of the 
aqueous ethanol extracts of dried aerial materials of the Salvia plants was determined using quercetin $0 \mathrm{mg} / \mathrm{L}, 5 \mathrm{mg} / \mathrm{L}$, $10 \mathrm{mg} / \mathrm{L}, 20 \mathrm{mg} / \mathrm{L}, 40 \mathrm{mg} / \mathrm{L}$, and $80 \mathrm{mg} / \mathrm{L}$ in $95 \%$ ethanol (Sigma-Aldrich, South Africa) as standard. In the sample wells, $12.5 \mu \mathrm{L}$ of the crude aqueous extracts were mixed with $12.5 \mu \mathrm{L} 0.1 \% \mathrm{HCl}$ (Merck, South Africa) in 95\% ethanol and $225 \mu \mathrm{L} 2 \% \mathrm{HCl}$ and incubated at room temperature for $30 \mathrm{~min}$. The absorbance was read at $360 \mathrm{~nm}$, at a temperature of $25^{\circ} \mathrm{C}$. The results were expressed as mg quercetin equivalent per g dry weight (mg QE/g DW) (Espinoza et al. 2019).

\section{Statistical analysis}

The plant height, crown width, total phenolic, and MIC data are reported as Mean $\pm \mathrm{SE}$, and the one-way analysis of variance (ANOVA) was used to compare the means amongst the treatments. The number of stems and leaves in the different treatments were compared using the Kruskal-Wallis test because they are count data. All computations were completed with the software programmes STATISTICA ${ }^{\circledR}(13.5 .0 .17)$ and the Paleontological Statistics package for education and data analysis (PAST 3.14). Post hoc analysis based on the Tukey test was used to separate the means for the plant height and crown width, total phenolic, and MIC data, while the Mann-Whitney test was used to analyse the data for the number of stems and leaves. $P$-values of $<0.05$ were regarded as significant, and $P$-values of $<0.01$ as very significant.

\section{Ethical considerations}

This study followed all ethical standards and received ethical clearance from Ethical Committee of the Faculty of Applied Sciences, Cape Peninsula University of Technology.

\section{Results}

\section{Height and crown width}

The heights of $S$. dolomitica plants varied significantly amongst the watering interval treatments $(d f=3,48 ; F=18.95$;
$P<0.01)$. Treatment two (6-day watering interval) had the highest mean height of $315 \mathrm{~mm}$, followed by the shortest watering interval (3-day watering interval) with a mean of $304.5 \mathrm{~mm}$. Treatments three (9-day watering interval) and four (12-day watering interval) recorded the shortest plants with $224.6 \mathrm{~mm}$ and $182.6 \mathrm{~mm}$, respectively.

There was also a significant difference $(P<0.01)$ in the heights of the $S$. namaensis plants between treatments (make $d f=3,48 ; F=5.345 ; P=0.004875)$. Treatment one had the highest mean height of $198 \mathrm{~mm}$, followed by treatment two with a mean height of $160 \mathrm{~mm}$. The lowest means were obtained in treatment three, $145 \mathrm{~mm}$, and treatment four, with a mean of $132.5 \mathrm{~mm}$.

A significant difference in the crown widths of the $S$. dolomitica plants $(d f=3,48 ; F=22.24 ; P<0.01)$ was observed with the largest widths belonging to treatment 1 (3-day watering interval) with a mean of $134.5 \mathrm{~mm}$ followed by treatment two and treatment three with measurements of $119.41 \mathrm{~mm}$ and $97.50 \mathrm{~mm}$, respectively. Treatment four had the lowest mean of $63.33 \mathrm{~mm}$ (Figure 1).

There was a significant difference $(P<0.05)$ in the crown width of the $S$. namaensis plants $(d f=3,48 ; F=3.312 ; P=$ $0.03433)$. The widest crown size measurements belonged to treatment two with a mean of $213.3 \mathrm{~mm}$, followed by treatment one $206.9 \mathrm{~mm}$. Treatments three and four both had the lowest mean of $145 \mathrm{~mm}$ each.

\section{Fresh and dry weights}

There was a significant difference in the fresh weights of the S. dolomitica plants $(d f=3,48 ; F=61.62 ; P<0.01)$. Treatment one, with the shortest watering interval, had the highest mean fresh weight of $11.25 \mathrm{~g}$, followed by treatments two and three with fresh weights of $8.9 \mathrm{~g}$ and $4.13 \mathrm{~g}$, respectively. Treatment four had the lowest mean fresh weight (1.52 g)

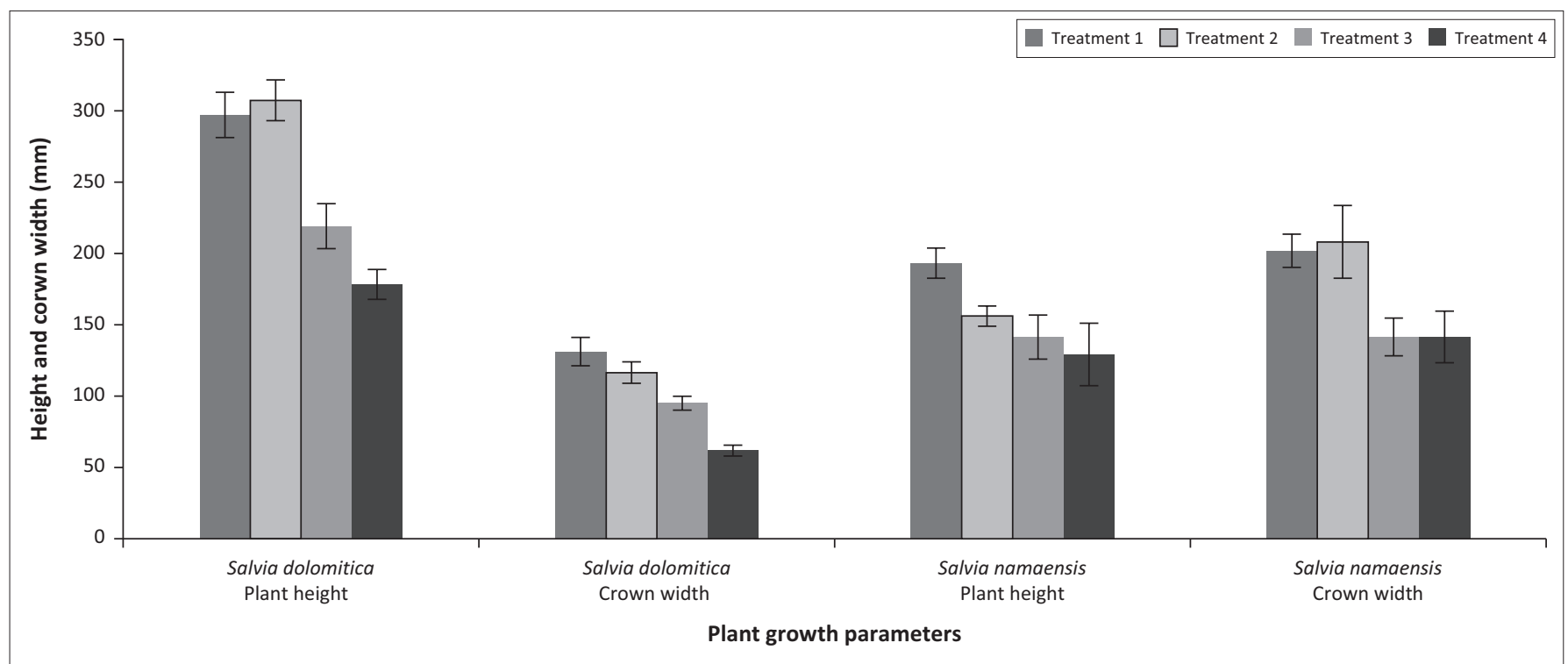

FIGURE 1: Means of plant heights and crown widths of Salvia dolomitica and Salvia namaensis plants subjected to four different water deficit treatments. 
(Table 1). A significant difference was also found in the fresh weights of the $S$. namaensis plants $(d f=3,48 ; F=58.56$; $P<0.01)$. Treatment one had the highest mean of $8.52 \mathrm{~g}$, followed by treatments two and three with $3.52 \mathrm{~g}$ and $1.46 \mathrm{~g}$, respectively. Treatment four had the lowest mean fresh weight $(1.15 \mathrm{~g})$. There was a significant difference in the dry weight of the $S$. dolomitica plants $(d f=3,48 ; F=22.72$; $P<0.01)$. Treatment one had the highest mean dry weight $(3.98 \mathrm{~g})$, followed by treatments two and three with measurements of $3.46 \mathrm{~g}$ and $1.85 \mathrm{~g}$, respectively. Treatment four had the lowest mean of $1.37 \mathrm{~g}$ (Table 1).

Results also show a significant difference in the dry weight of the $S$. namaensis plants $(d f=3,48 ; F=31.6 ; P<0.01)$. Treatment one had the highest mean dry weights (3.69 $\mathrm{g} \pm 0.29 \mathrm{~g})$, followed by treatments two and three, with measurements of $2.14 \mathrm{~g} \pm 0.26 \mathrm{~g}$ and $1.38 \mathrm{~g} \pm 0.26 \mathrm{~g}$, respectively. Treatment four had the lowest mean of $1.01 \mathrm{~g}$ (Table 1).

\section{Number of stems and leaves}

Because of the nature of the growth habit of S. namaensis, the number of stems and leaves for the different treatments have not been recorded as they are too numerous to count, and even mild to moderate water deficit treatments made the leaves too brittle to handle. The data for S. dolomitica is presented in Table 2. The number of stems and number of leaves decreased with increasing water stress. There was no statistical difference found between treatments of the number of stems of the $S$. dolomitica plants $\left(d f=3 ; \chi^{2}=27.43 ; P=\right.$ 0.1107) subjected to different water-deficit treatments. Treatment one had the highest mean recorded for the stems $(3.07 \pm 0.66)$, while the lowest mean number of stems $(1.38 \pm$ 0.21 ) was recorded for treatment four (Table 2). A significant difference was found amongst treatments for the number of leaves $\left(d f=3 ; \chi^{2}=34.05 ; P<0.001\right)$ of the $S$. dolomitica plants subjected to different water-deficit treatments. Treatment one had the highest mean number of leaves $(109.15 \pm 9.71)$, while the lowest mean number of leaves $(44.33 \pm 4.33)$ was recorded for treatment four.

\section{Polyphenols in mg gallic acid equivalents/g}

There was no statistical difference in total polyphenol content amongst the treatments for the $S$. dolomitica $(d f=3,8 ; F=107$;

TABLE 1: The mean \pm standard error fresh and dry weights of Salvia dolomitica and Salvia namaensis species subjected to four different water-deficit treatments.

\begin{tabular}{lcc}
\hline Salvia species & Fresh weight & Dry weight \\
\hline Salvia namaensis & $11.25 \pm 0.93 \dagger$ & $3.98 \pm 0.43 \dagger$ \\
Treatment one & $8.90 \pm 0.50 \dagger$ & $3.46 \pm 0.23 \dagger$ \\
Treatment two & $4.13 \pm 0.35 \S$ & $1.85 \pm 0.14 \dagger$ \\
Treatment three & $1.52 \pm 0.12 \uparrow$ & $1.37 \pm 0.10 \dagger$ \\
Treatment four & & \\
Salvia dolomitica & $8.52 \pm 0.64 \dagger$ & $3.69 \pm 0.29 \dagger$ \\
Treatment one & $3.52 \pm 0.48 \dagger$ & $2.14 \pm 0.26 \dagger$ \\
Treatment two & $1.46 \pm 0.12 \S$ & $1.38 \pm 0.11 \dagger, \S$ \\
Treatment three & $1.15 \pm 0.08 \S$ & $1.01 \pm 0.07 \S$ \\
Treatment four &
\end{tabular}

Note: The values tabulated are the means \pm SE of fresh and dry weights, 13 replicates. Significant differences amongst the means are evaluated using the Tukey's HSD test. Values with the same symbols in a column are not significantly different at the 0.05 probability level.
$P=0.4147)$. However, treatment three recorded the highest mean of $73.67 \mathrm{GAE} / \mathrm{g} \pm 4.91 \mathrm{GAE} / \mathrm{g}$ and treatment four had the lowest total polyphenol content tested, recording a mean of 64.39 GAE/g $\pm 3.40 \mathrm{GAE} / \mathrm{g}$ (see Table 3).

Similarly, no statistical difference in total polyphenol content was observed amongst the treatments for the $S$. namaensis $(d f=3,8 ; F=1.986 ; P=0.1947)$. However, treatment one had the highest total polyphenol content, $61.22 \mathrm{GAE} / \mathrm{g} \pm 1.79$ $\mathrm{GAE} / \mathrm{g}$, followed by treatment two, $55.33 \mathrm{GAE} / \mathrm{g} \pm 2.31$ $\mathrm{GAE} / \mathrm{g}$ and treatment three, $52.88 \mathrm{GAE} / \mathrm{g} \pm 3.53 \mathrm{GAE} / \mathrm{g}$, and the lowest amount recorded was from treatment four with 51.57 GAE/g \pm 3.97 GAE/g (Table 3).

\section{Flavanols in $\mathrm{mg}$ quercetin equivalent/g}

There was no statistical difference in the total flavanol contents in the extracts of the differently treated S. dolomitica plant $(d f=3,8 ; F=2.401 ; P=0.1432)$. The values of $\mathrm{mg}$ $\mathrm{QE} / \mathrm{g}$ ranged from $8.09 \mathrm{mg} \mathrm{QE} / \mathrm{g} \pm 0.11 \mathrm{mg} \mathrm{QE} / \mathrm{g}$ to 10.36 $\mathrm{mg} \mathrm{QE} / \mathrm{g} \pm 0.76 \mathrm{mg} \mathrm{QE} / \mathrm{g}$, with treatment four containing the lowest amount of flavanols and treatment three the highest (Table 3). Treatments one and two contained 8.84 $\mathrm{mg} \mathrm{QE} / \mathrm{g} \pm 0.90 \mathrm{mg} \mathrm{QE} / \mathrm{g}$ and $8.53 \mathrm{mg} \mathrm{QE} / \mathrm{g} \pm 0.48 \mathrm{mg}$ $\mathrm{QE} / \mathrm{g}$, respectively.

On the other hand, flavanol contents in S. namaensis plants varied significantly amongst the treatments $(d f=3,8 ; F=5.171$; $P=0.02811$ ), with the shortest watering interval, treatment 1 , yielding the highest amount $8.24 \mathrm{mg} \mathrm{QE} / \mathrm{g} \pm 0.30 \mathrm{mg} \mathrm{QE} / \mathrm{g}$, followed by treatment two $7.45 \mathrm{mg} Q E / g \pm 0.44 \mathrm{mg} \mathrm{QE} / \mathrm{g}$ and treatment four with $06.33 \mathrm{mg} Q E / g \pm 0.60 \mathrm{mg} Q E / g$. Treatment

TABLE 2: The mean \pm standard error number of stems and leaves of Salvia dolomitica subjected to four different water-deficit treatments.

\begin{tabular}{lcc}
\hline Species: Salvia dolomitica & Number of stems & Number of leaves \\
\hline Treatment one & $3.07 \pm 0.66 \dagger$ & $109.15 \pm 9.71 \dagger$ \\
Treatment two & $1.84 \pm 0.37 \dagger$ & $90.46 \pm 6.22 \dagger$ \\
Treatment three & $1.53 \pm 0.31 \dagger$ & $58.08 \pm 6.07 \dagger$ \\
Treatment four & $1.38 \pm 0.21 \dagger$ & $44.33 \pm 4.33 \dagger$ \\
\hline
\end{tabular}

Note: The values tabulated are the means \pm SE of the number of stems and leaves, 13 replicates. Means \pm SE with the same symbols in a column are not significantly different at the 0.05 probability level following a Mann-Whitney test.

TABLE 3: The mean \pm standard error of polyphenols, flavanols and alkaloids present in extracts of $S$. dolomitica and $S$. namaensis subjected to four different water-deficit treatments.

\begin{tabular}{lccc}
\hline Salvia species & $\begin{array}{c}\text { Polyphenols in } \\
\text { mg GAE/g }\end{array}$ & $\begin{array}{c}\text { Flavanols in } \\
\text { mg QE/g }\end{array}$ & Alkaloids in mg AE/g \\
\hline Salvia namaensis & & & \\
Treatment one & $66.43 \pm 5.23 \dagger$ & $08.84 \pm 0.90 \dagger$ & $05.91 \pm 0.33 \dagger, \dagger$ \\
Treatment two & $64.51 \pm 2.96 \dagger$ & $08.53 \pm 0.48 \dagger$ & $04.57 \pm 0.26 \dagger$ \\
Treatment three & $73.67 \pm 4.91 \dagger$ & $10.36 \pm 0.76 \dagger$ & $06.67 \pm 0.54 \dagger$ \\
Treatment four & $64.39 \pm 3.40 \dagger$ & $08.09 \pm 0.11 \dagger$ & $04.75 \pm 0.53 \dagger, \dagger$ \\
Salvia dolomitica & & & \\
Treatment one & $61.22 \pm 1.79 \dagger$ & $08.24 \pm 0.30 \dagger$ & $02.10 \pm 0.20 \dagger$ \\
Treatment two & $55.33 \pm 2.31 \dagger$ & $07.45 \pm 0.44 \dagger, \dagger$ & $02.89 \pm 0.30 \dagger$ \\
Treatment three & $52.88 \pm 3.53 \dagger$ & $06.13 \pm 0.34 \dagger$ & $02.75 \pm 0.68 \dagger$ \\
Treatment four & $51.57 \pm 3.97 \dagger$ & $06.33 \pm 0.60 \dagger, \dagger$ & $04.05 \pm 0.96 \dagger$ \\
\hline
\end{tabular}

Note: Values with the same symbols in a column are not significantly different at the 0.05 probability level. Significant differences amongst the means were evaluated using the Tukey's HSD test.

$\mathrm{GAE}$, gallic acid equivalents; $\mathrm{QE}$, quercetin equivalent; $\mathrm{AE}$, atropine equivalent. 
three contained the lowest with a value of $6.13 \mathrm{mg} \mathrm{QE} / \mathrm{g} \pm$ $0.34 \mathrm{mg} \mathrm{QE} / \mathrm{g}$ (Table 3).

\section{Alkaloids $\mathrm{mg}$ atropine equivalent/g}

Extracts of $S$. dolomitica exposed to treatment three $(6.67 \mathrm{mg}$ $\mathrm{QE} / \mathrm{g} \pm 0.54 \mathrm{mg} \mathrm{AE} / \mathrm{g}$ ) produced significantly higher alkaloid content compared to the other treatments $(d f=3,8 ; F$ $=5.211 ; P=0.02758)$ (Table 3).

No statistical difference in total alkaloid contents $(P>0.05)$ was observed amongst the treatments $(d f=3,8 ; F=1.716$; $P=0.2405)$ of the $S$. namaensis extracts. The values of $\mathrm{mg} \mathrm{AE} / \mathrm{g}$ ranged from $2.10 \mathrm{mg} \mathrm{QE} / \mathrm{g} \pm 0.20 \mathrm{mg} \mathrm{AE} / \mathrm{g}$ to $4.05 \mathrm{mg} \mathrm{QE} / \mathrm{g} \pm 0.96 \mathrm{mg} \mathrm{AE} / \mathrm{g}$, with the treatment one having the lowest and treatment four the highest (Table 3). Treatment two and three contained $2.89 \mathrm{mg} Q E / g \pm 0.30$ $\mathrm{mg} \mathrm{AE} / \mathrm{g}$ and $2.75 \mathrm{mg} \mathrm{QE} / \mathrm{g} \pm 0.68 \mathrm{mg} \mathrm{AE} / \mathrm{g}$, respectively.

\section{Antifungal activity in a micro-dilution bioassay Minimum inhibitory concentration of Salvia dolomitica extracts}

There was a significant difference $(P<0.01)$ amongst treatments after the 6 th and 12th hour of incubation $(d f=4$, $10 ; F=7.51 ; P<0.01)$. The mild, treatment two, and moderate, treatment three, water deficit treatments produced higher activity than the synthetic fungicide, Mancozeb (Figure 2).

A significant difference was observed amongst the treatments at the 18th hour of incubation $(d f=4,10 ; P<0.01)$. Treatments one, two, and three each had a MIC of $1.5 \mathrm{mg} / \mathrm{mL}$, followed by treatment four with a recording of $3 \mathrm{mg} / \mathrm{mL}$. All the treatments showed fungistatic activity higher than Mancozeb, which had a MIC value of $6 \mathrm{mg} / \mathrm{mL}$ (Figure 2).

After $24 \mathrm{~h}$ of incubation there was significant differences in the fungistatic activity of the acetone extracts of $S$. dolomitica $(d f=$ $4,10 ; P<0.01)$. All the treatments had higher activity than the synthetic fungicide, Mancozeb that had a MIC reading of $6 \mathrm{mg} / \mathrm{mL}$ at this period. Treatment one and treatment four recorded a MIC value of $3 \mathrm{mg} / \mathrm{mL}$, and both treatment two and three recorded a better MIC value of $1.5 \mathrm{mg} / \mathrm{mL}$.

\section{Minimum inhibitory concentration of Salvia namaensis extracts}

There was a significant difference amongst treatments at 6 and $12 \mathrm{~h}$ of incubation $(d f=4,10 ; F=1.5 ; P<0.01)$ (Figure 3). Treatment one and treatment four, both having a MIC of $6 \mathrm{mg} / \mathrm{mL}$, showed weaker activity than that of Mancozeb, which had a reading of $3 \mathrm{mg} / \mathrm{mL}$. Treatment three was comparable to that of Mancozeb with the same MIC value, and treatment two showed the highest activity of $1.5 \mathrm{mg} / \mathrm{mL}$ of the extracts tested (Figure 3).

Treatment two had significantly higher fungistatic activity than the other treatments $(d f=4,10 ; F=5.4 ; P<0.01)$ with a MIC of $3 \mathrm{mg} / \mathrm{mL}$ (Figure 3). A reading of $6 \mathrm{mg} / \mathrm{mL}$ was observed at the 18th hour of incubation for treatment one, treatment three, treatment four, and the synthetic fungicide, Mancozeb.

There was no change in the MIC values at $24 \mathrm{~h}$ MICs for treatments one, three, and four which were comparable to the fungistatic activity of Mancozeb. All had a MIC value of $6 \mathrm{mg} / \mathrm{mL}$.

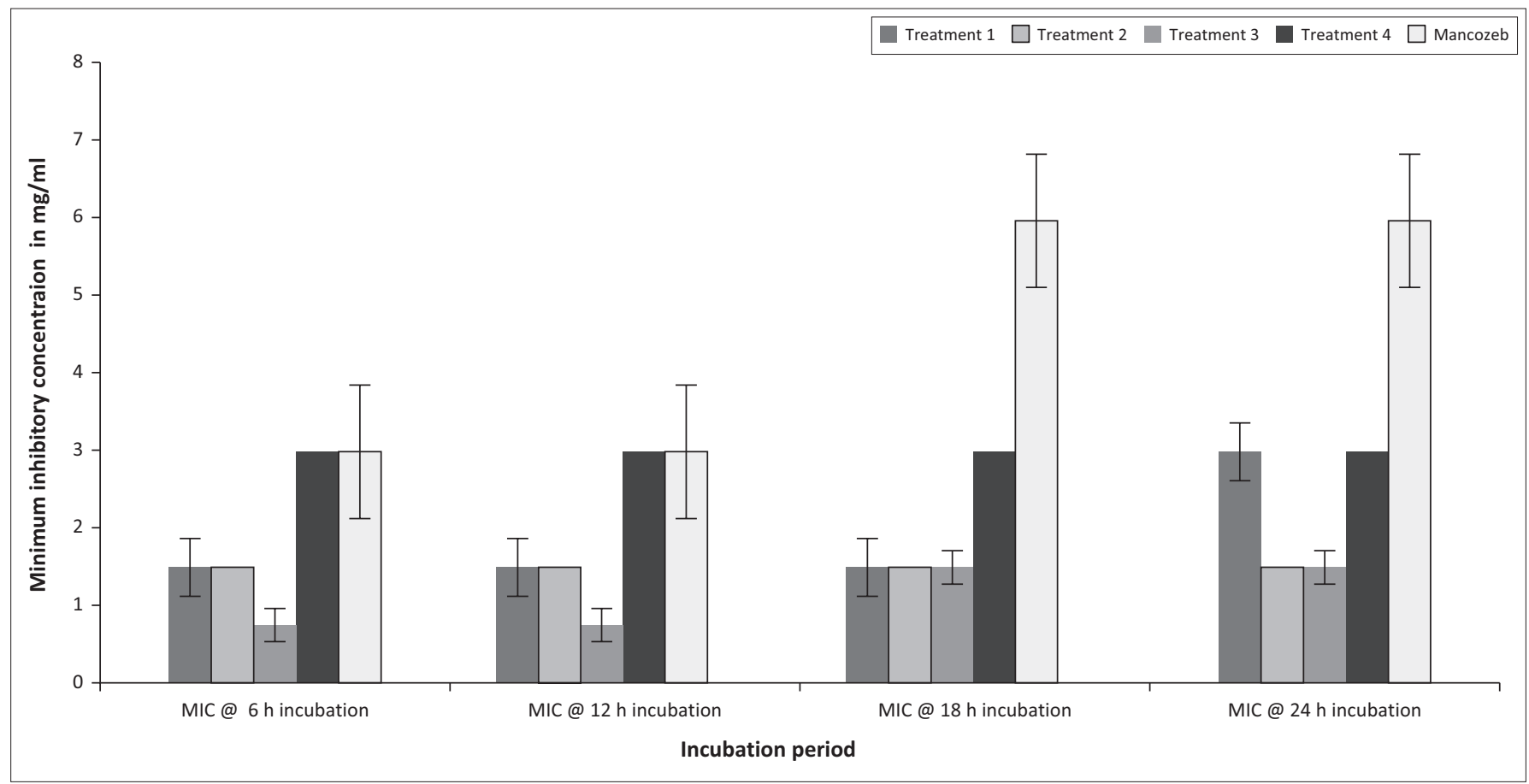

MIC, minimum inhibitory concentration.

FIGURE 2: Minimum inhibitory concentration values (mean \pm standard error $\mathrm{mg} / \mathrm{mL}$ ) of Salvia dolomitica leaf extracts, subjected to different water deficit treatments, against Fusarium oxysporum. 


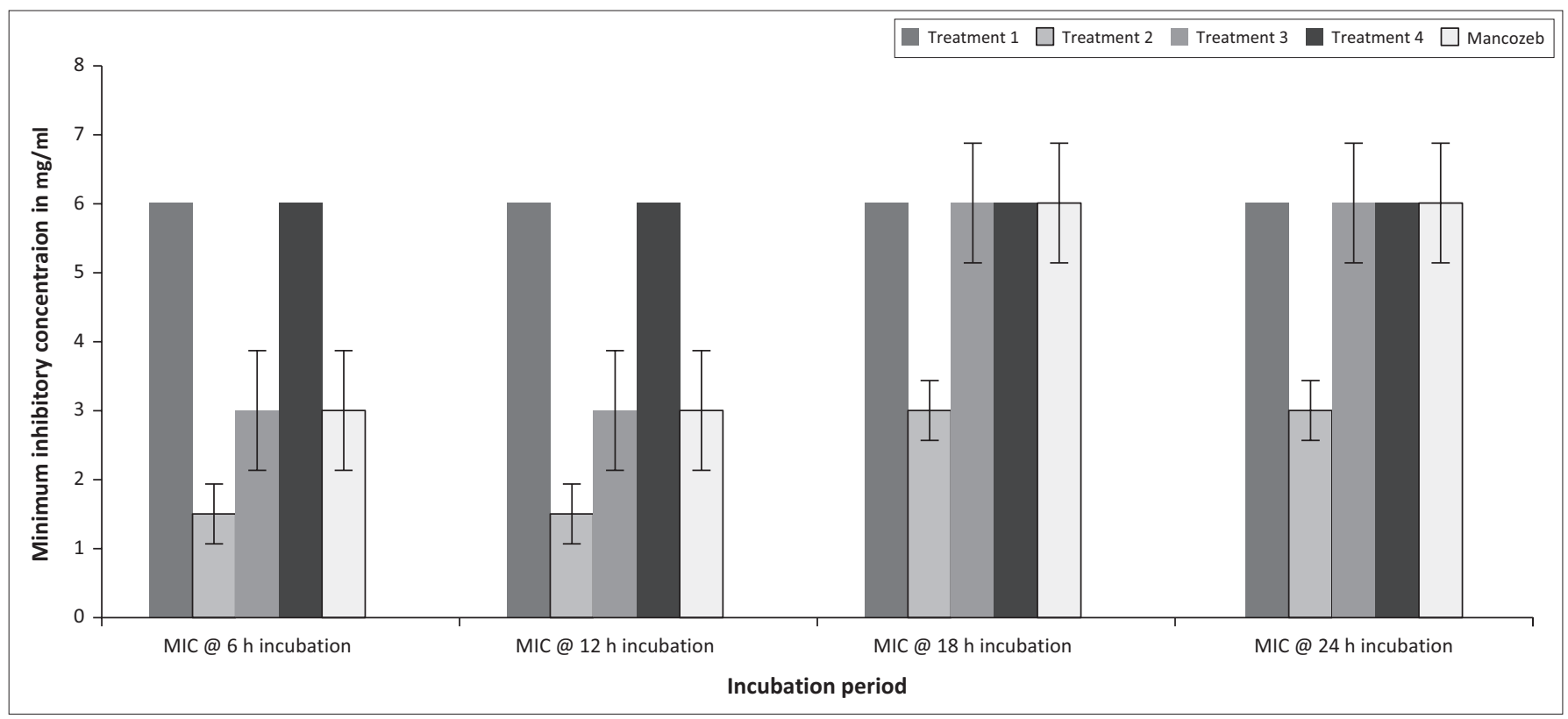

MIC, minimum inhibitory concentration; $h$, hour.

FIGURE 3: Minimum inhibitory concentration values (mean \pm standard error $\mathrm{mg} / \mathrm{mL}$ ) of Salvia namaensis leaf extracts, subjected to different water deficit treatments, against Fusarium oxysporum.

\section{Discussion}

Water deficit is one of the most important factors affecting plant growth and poses a substantial threat to sustainable agriculture (Ings et al. 2013). This study's findings suggest that increasing water deficits lead to a decrease in plant height and crown width in S. dolomitica and S. namaensis plants overall. These agree with the findings of Rahimi, Taleei and Ranjbar (2017) who found that dehydration reduces overall plant growth as a result of the considerable reduction of photosynthesis, cell turgidity, cell growth, and increasing evapotranspiration. Moderate water deficit did increase the length of $S$. dolomitica and the crown width of S. namaenis plants in the current study. Similar findings were reported by Luvaha, Netondo and Ouma (2008), who found that mild water deficits had a positive effect on the stem length of Mangifera indica. Guo et al. (2016) also showed that the height and crown width of L. ruthenicum increases under mild water deficit conditions.

The fresh and dry weights decreased as the water deficits increased for all the treatments of both species of Salvia tested in this study. However, the drop in fresh weight is more drastic than the decrease in dry weight. Ramos et al. (1999) showed that water deficit inhibits the accumulation of fresh plant mass significantly than dry biomass of the common bean plant (Phaseolus vulgaris L.). Malejane et al. (2018) concluded, based on their trial, that overall, increasing water deficit impacted negatively on the fresh weight of both the green leafy lettuce cultivars tested. Water deficit also reduced the plant height, crown width, fresh and dry mass of Melissa officinalis L. (Radácsi et al. 2016). In this study, the number of leaves and stems of $S$. dolomitica significantly decreased as the water deficits' intensity increased. These findings can be corroborated by Gugliuzza et al. (2020) study, in which drought reduced all growth in Loquat plants (Eriobotrya japonica). Radácsi et al. (2016) showed that water-deficit levels significantly affected the quantity and quality of lemon balm plants.

The abiotic factor, water deficit stress, is one of the most common environmental factor that affects plant growth (Bohnert \& Jensen 1996; Xu et al. 2010), and is considered one of the most growth-limiting factor that decreases plant growth (Tátrai et al. 2016). Drought stress occurs when the available water in the soil is reduced to critical levels. Drought stress tolerance is seen in all plants, yet the extent of tolerance varies from species to species. Exposure to drought causes many common reactions in plants, such as cellular dehydration, which causes osmotic stress and water removal from the cytoplasm to vacuoles (Ramakrishna \& Ravishankar 2011). A reduction in chlorophyll content may occur under drought stress (Massacci et al. 2008). Water deficits can adversely impact many aspects of the physiology of plants, especially photosynthetic capacity, and prolonged drought stress may severely diminish plant growth and productivity (Osakabe et al. 2014). Water stress affects plants' photosynthesis by reducing the carbondioxide conductance in leaves because of the changes in the stomatal aperture with the decrease in the leaf water potential. In some plants, the translocation of photoassimilates from leaves to the stems assists in the maintenance of growth under water stress conditions (Li et al. 2009; Ohashi, Saneoka \& Fujita 2000).

The effects of water-stress on phenolic content varied with plant species in this study, suggesting that water deficit can increase or decrease phytochemicals in plants (Umebese \& Falana 2013). Specifically, moderate water deficit treatment increased the level of polyphenols in the extracts of S. dolomitica. Similar results were obtained by Marchese et al. (2010) when they examined the effect of water deficits on accumulating biomass and artemisinin in annual wormwood (Artemisia annua L.) and results showed that moderate water deficit not 
only induced artemisinin accumulation, but also reduced time and costs in drying the crop. These factors, in combination, increase crop profit margins coupled with water-saving and can only lead to further mitigation of environmental degradation and sustainable business practices.

According to McKiernan et al. (2017) juvenile Eucalyptus globulus can tolerate periods of continuous yet moderate water availability with little impact on concentrations of secondary plant metabolites. On the other hand, increasing water deficits resulted in a decrease in polyphenolic content in S. namaensis, which contrasts with the results recorded by Lee and Oh (2017) in their study on the effects of water deficits on the contents of bioactive compounds in Dropwort; the total phenolic contents of all the water deficit treatments increased significantly compared to the controls. A study by Giamperi et al. (2012) compared the total content of polyphenolic compounds in eight Salvia spp. exudates and reported that the second highest concentration of polyphenols was detected in S. namaensis with $20 \mu \mathrm{g}$ polyphenols recorded. It is interesting that the water deficit treatments in this study did not have a positive effect on the accumulation of polyphenols in S. namaensis. The levels of phenolic compounds in plants are genetically controlled and environmentally induced (Lattanzio 2013). Further study on the effects of abiotic factors on the polyphenolic content of this species is recommended.

This study indicates that moderate water deficits increased the flavanol content of $S$. dolomitica extracts, and mild and severe water deficit treatments decreased the flavanols' levels. However, the effect of water deficits on flavanol content was not significant $(P>0.05)$. Umebese and Falana (2013) investigated the impact of water stress on the concentrations of phytochemicals of Bryophyllum pinnatum L. and found that flavonoids increased with increased water deficit intervals. Various biotic and abiotic stress affect the accumulation of flavonoids in plant vegetative tissues and organs (Braidot et al. 2008). Water deficits affect the accumulation of flavonoids in plants (Hernandez, Alegre \& Munne-Bosch 2004). The results of a trial by Yuan et al. (2012) clearly showed that water deficit affected flavonoid accumulation by regulating hormone metabolism in Scutellaria baicalensis. All the water deficit treatments significantly $(P<0.05)$ decreased the $S$. namaensis extracts' flavanol content compared to the controls (treatment 1). Radácsi et al. (2016) also found that under two of the stress treatments they subjected Melissa officinalis plants to the accumulation of flavonoids was decreased by $14 \%-22 \%$.

As was the case in the flavanol content of the extracts in this study, mild and severe water deficit treatments significantly $(P<0.05)$ decreased the alkaloid content in the $S$. dolomitica extracts, but an increase in alkaloid content was observed in the extracts exposed to moderate water deficits, significantly more than the extracts treated to mild water deficits. With the S. namaensis extracts, the alkaloid content increased as the level of water deficits increased; the association was not significant. Alkaloids are secondary metabolites synthesised and accumulated by many higher plant species (Umebese, Okunade \& Orotope 2012). Several alkaloids affect the biological function of fungi at low concentrations (Singh, Pandey \& Singh 2007). The differences in accumulation of secondary metabolites of Salvia species at various degrees of water deficits may be because of the genetic makeup of the individual species (Isah 2019; Matveeva, Sokornova \& Lutova 2015) as well as changes in nutrient uptake which may cause changes in secondary metabolite production (Prescott et al. 2020).

The extracts of $S$. dolomitica plants exposed to mild and moderate water deficits displayed significantly better fungistatic activity against $F$. oxysporum than the controls, the severe water deficit treated extracts, and the synthetic fungicide Mancozeb. With the $S$. namaensis, the mild water deficit treated extracts displayed more potent activity than all other treatments. Broadly, these results suggested that mild to moderate water stress enhances antifungal activity of acetone extracts of both Salvia spp. studied. When El Bouzidia et al. (2012) examined the anti-fungal activities of Achillea ageratum against Candida species, they claimed that the MIC values ranging from $5.83 \mathrm{mg} / \mathrm{mL}$ to $8.42 \mathrm{mg} / \mathrm{mL}$ were quite remarkable. In this study, the MIC values ranged from $0.075 \mathrm{mg} / \mathrm{mL}$ to $6 \mathrm{mg} / \mathrm{mL}$ for $S$. dolomitica extracts and $1.5 \mathrm{mg} / \mathrm{mL}-6 \mathrm{mg} / \mathrm{mL}$ for $S$. namaensis extracts. They can, therefore, also be considered as remarkable levels of antifungal activity. The anti-fungal activity of the tested extracts can be correlated to the changes in the phenolic content when subjected to water deficits. Similarly, results of the study on the antimicrobial properties of ethanol extracts of Gymnema montanum L. against Salmonella typhi, Pseudomonas aeruginosa, and Candida albicans indicated that the presence of antimicrobial properties in the leaf extract of G. montanum correlated to its phenolic compound content (Devi et al. 2017).

\section{Conclusion and recommendations}

The results if the present study indicate that the cultivation of S. dolomitica under mild and moderate water deficits correlated with their alkaloid metabolites as well as the fungistatic activity of the acetone extracts against F. oxysporum. However, the data presented here reflect in vitro and greenhouse experiments, and it is recommended that field experiments and further investigations need to be conducted to confirm this conclusion. The application of controlled water deficits during the cultivation of medicinal plants will save water, freeing up water for other uses or decreasing the water bill and enhancing profit margins of medicinal plant cultivators. Saving water is critical for a water-scarce country like South Africa.

Based on the results of this study, it is possible to speculate that moderate water stress can be beneficial for secondary metabolite production of Salvia spp. and this knowledge could be further exploited by pharmaceutical industries to develop new drugs and formulations.

\section{Acknowledgements}

The authors thank Cape Peninsula University of Technology for funding this study. 


\section{Competing interests}

The authors declare that they have no financial or personal relationships that may have inappropriately influenced them in writing this article.

\section{Authors' contributions}

S.R. and F.N. conceptualised the study and designed the experiment. S.R. performed the experiment, interpreted data and prepared the draft manuscript. F.N. corrected the manuscript and supervised the research. S.R. and F.N. revised the final version of the manuscript.

\section{Funding information}

This research was funded by Cape Peninsula University of Technology (Grant no. URF R166). Mr. S. Roos received financial support from the National Research Foundation of South Africa (Grant Numbers: 112195).

\section{Data availability}

The data will be stored at the Cape Peninsula University of Technology.

\section{Disclaimer}

The views and opinions expressed in the article are those of the authors and do not necessarily reflect the official policy or position of any affiliated agency of the authors.

\section{References}

Al-Gabbiesh, A., Kleinwächter, M. \& Selmar, D., 2014, 'Influencing the contents of secondary metabolites in spice and medicinal plants by deliberately applying drought stress during their cultivation', Jordan Journal of Biological Sciences 8(1), drought stress during their cultivation', Jor
$1-10$. https://doi.org/10.12816/0026941

Antonucci, M., 2016, Medicinal herbs in high demand help address poverty in drylands of India Research Program on Dryland Systems, viewed 22 March 2017, from http://drylandsystems.cgiar.org/outcome-stories/medicinal-herbs-high-demandhttp://drylandsystems.cgiar.org/outcom
help-address-poverty-drylands-india.

Arif, T., Bhosale, J., Kumar, N., Mandal, T., Bendre, R. Lavekar, G. et al., 2009, 'Natural products - Anti-fungal agents derived from plants', Journal of Asian Natural Products Research 11(7), 621-638. https://doi. Natural Products Research
org/10.1080/10286020902942350

Berini, J., Brockman, S., Hegeman, A., Reich, P., Muthukrishnan, R., Montgomery, R. et al., 2018, 'Combinations of abiotic factors differentially alter production of plant secondary metabolites in five woody plant species in the boreal-temperate transition zone', Frontiers in Plant Science 9, 1257. https://doi.org/10.3389/ transition zone',
fpls.2018.01257

Bohnert, H. \& Jensen, R., 1996, 'Strategies for engineering water-stress tolerance in plants', Trends in Biotechnology 14(3), 89-97.

Braidot, E., Zancani, M., Petrussa, E., Peresson, C. \& Bertolini, A., 2008, 'Transport and accumulation of flavonoids in grapevine (Vitis vinifera L.)', Plant Signaling and Behavior 3(9), 626-632. https://doi.org/10.4161/psb.3.9.6686

Caretto, S., Linsalata, V., Colella, G., Mita, G. \& Lattanzio, V., 2015, 'Carbon fluxes between primary metabolism and phenolic pathway in plant tissues under stress', International Journal of Molecular Sciences 16(11), 26378-26394. https://doi. org/10.3390/ijms161125967

Chen, S., Yu, H., Luo, H., Wu, Q., Li, C. \& Steinmetz, A., 2016, 'Conservation and sustainable use of medicinal plants: Problems, progress, and prospects', Chinese Medicine 11(37), 1-31. https://doi.org/10.1186/s13020-016-0108-7

Clebsch, B., 2003, The new book of Salvias: Sages for every garden, pp. 102-104, 108-109, Timber Press Inc., Portland, OR.

Devi, P., Murugan, S., Suja, S., Selvi, S., Chinnaswamy, P. \& Vijayanand, E., 2007 'Antibacterial, in vitro lipid per oxidation and phytochemical observation on achyranthes bidentata Blume', Pakistan Journal of Nutrition 6(5), 447-451. https://doi.org/10.3923/pjn.2007.447.451

Donnenfeld, Z., Crookes, C. \& Hedden, S., 2018, A delicate balance. Water scarcity in South Africa, Institute for Security Studies, viewed 04 May 2019, from https://issafrica.org/ research/southern-africa-report/a-delicate-balance-water-scarcity-in-south-africa.
El Bouzidia, L., Abbad, A., Hassanib, L., Fattarsic, K., Leachd, D., Markouka, M. et al., 2012, 'Essential oil composition and antimicrobial activity of wild and cultivated Moroccan L.: A rare and threatened medicinal species', Chemistry \& Biodiversity Moroccan L.: A rare and threatened medicinal species', Che
9(3), 598-605. https://doi.org/10.1002/cbdv.201100115

Espinoza, F., Vidal, S., Rautenbach, F., Lewu, F. \& Nchu, F., 2019, 'Effects of Beauveria bassiana (Hypocreales) on plant growth and secondary metabolites of extracts of hydroponically cultivated chive (Allium schoenoprasum L. [Amaryllidaceae])', hydroponically cultivated chive (Allium schoenoprasum L. [Am
Heliyon 5, e03038. https://doi.org/10.1016/j.heliyon.2019.e03038

Fadhil, S., Reza, M., Rouhollah, G. \& Reza, V., 2007, 'Spectrophotometric determination of total alkaloids in Penganum harmala L. using Bromocresol Green', Research Journal pf Phytochemistry 1(2), 79-82.

Giamperi, L., Bucchini, A., Bisio, A., Giacomelli, E., Romussi, G. \& Ricci, D., 2012, 'Total phenolic content and antioxidant activity of Salvia spp. Exudates', Natural Product Communications 7(2), 201-202.

Goldin. J., 2010, 'Water policy in South Africa: Trust and knowledge as obstacles to reform', Review of Radical Political Economics 42(2), 195-212. https://doi. org/10.1177/0486613410368496

Gugliuzza, G., Talluto, G., Martinelli, F., Farina, V. \& Bianco, R., 2020, 'Water deficit affects the growth and leaf metabolite composition of young loquat plants', Plants $9(2), 274$.

Guo, Y., Yu, H., Kong, D., Yan, F. \& Zhang. Y., 2016, 'Effects of drought stress on growth and chlorophyll fluorescence of Lycium ruthenicum Murr. seedlings' Photosynthetica 54(4), 524-531. https://doi.org/10.1007/s11099-016-0206-x

Hernandez, I., Alegre, L. \& Munne-Bosch, S., 2004, 'Drought-induced changes in flavonoids and other low molecular weight antioxidants in Cistus clusii grown under Mediterranean field conditions', Tree Physiology 24(11), 1303-1311. https://doi.org/10.1093/treephys/24.11.1303

Ings, J., Mur, L., Robson, P. \& Bosch, M., 2013, 'Physiological and growth responses to water deficit in the bioenergy crop Miscanthus $\mathrm{x}$ giganteus', Frontiers in Plant Science 4, 468. https://doi.org/10.3389/fpls.2013.00468

Isah, T., 2019, 'Stress and defense responses in plant secondary metabolites production', Biologic Research 52(39), 1-25.

Ito, S., Ihara, T., Tamura, H., Tanaka, S., Ikeda, T. \& Kajihara, H., 2007, 'Alpha-Tomatine, the major saponin in tomato, induces programmed cell death mediated by reactive oxygen species in the fungal pathogen Fusarium oxysporum', FEBS Letters reactive oxygen species in the fungal pathogen Fusarium oxysporum',
581(17), 3217-3222. https://doi.org/10.1016/j.febslet.2007.06.010

Kamatou, G., Makunga, N., Ramogola, W. \& Viljoen, A., 2008, 'South African Salvia species: A review of biological activities and phytochemistry', Journal of Ethnopharmacology 119(3), 664-672. https://doi.org/10.1016/j.jep.2008.06.030

Kapoor, D., Bhardwaj, S., Landi, M., Sharma, A., Ramakrishnan, M. \& Sharma, A., 2020, 'The impact of drought in plant metabolism: How to exploit tolerance mechanisms to increase crop production', Applied Sciences 10(16), 1-19.

Kleinwächter, M. \& Selmar, D., 2015, 'New insights explain that drought stress enhances the quality of spice and medicinal plants: Potential applications' Agronomy for Sustainable Development 35, 121-131. https://doi.org/10.1007/ s13593-014-0260-3

Kroymann, J., 2011, 'Natural diversity and adaptation in plant secondary metabolism', Current Current Opinion in Plant Biology 14(3), 246-251.

Larson, R., 1998, 'The antioxidants of higher plants', Phytochemistry 27(4), 969-978. https://doi.org/10.1016/0031-9422(88)80254-1

Lattanzio, V., 2013, 'Phenolic compounds: Introduction', in K. Ramawat \& J. Me'rillon (eds.), Natural products, pp. 1544-1573, Springer-Verlag, Berlin.

Lee, J. \& Oh, M., 2017, 'Water deficit increases the contents of bioactive compounds in Dropwort', Horticulture, Environment and Biotechnology 58(5), 458-466.

Li, W., Hou, J., Wang, W., Tang, X., Liu, C. \& Xing, D., 2009, 'Effect of Water Deficit on Biomass production and accumulation of Secondary Metabolites in Roots of $G$. uralensis', Russian Journal of Plant Physiology 58(3), 538-542.

Luvaha, E., Netondo, G. \& Ouma, G., 2008, 'Effect of water deficit on the physiological and morphological characteristics of Mango (Mangifera indica) Rootstock seedlings', American Journal of Plant Physiology 3(1), 1-15. https://doi.org/10.3923/ ajpp.2008.1.15

Malejane, D., Tinyani, P., Soundy, P., Sultanabad, Y. \& Sivakumar, D., 2018, 'Deficit irrigation improves phenolic content and antioxidant activity in leafy lettuce varieties', Food Science and Nutrition 6(2), 334-341. https://doi.org/10.1002/fsn3.559

Marchese, J., Ferreira, J., Rehder, V. \& Rodrigues, O., 2010, 'Water deficit effect on the accumulation of biomass and artemisinin in annual wormwood (Artemisia annua L.)', Brazilian Journal of Plant Physiology 22(1), 1-9.

Massacci, A., Nabiev, S., Pietrosanti, L., Nematov, S., T N Chernikova, T., Thor, K. et al. 2008 , 'Response of the photosynthetic apparatus of cotton (Gossypium hirsutum) to the onset of drought stress under field conditions studied by gas-exchange analysis and chlorophyll fluorescence imaging', Plant Physiology and Biochemistry 46(2), 189-195. https://doi.org/10.1016/j.plaphy.2007.10.006

Matveeva, T.V., Sokornova, S. \& Lutova, L., 2015, 'Influence of Agrobacterium oncogenes on secondary metabolism of plants', Phytochemistry Reviews 14 541-554. https://doi.org/10.1007/s11101-015-9409-1

Mckiernan, A., Potts, B., Hovenden, M., Brodribb, T., Davies, N., Rodemann, T. et al., 2017 , 'A water availability gradient reveals the deficit level required to affect traits in potted juvenile Eucalyptus globulus', Annals of Botany 119(6), 1043-1052. https://doi.org/10.1093/aob/mcw266

Mcquillan, M., 2011, Salvia namaensis, viewed 01 June 2018, from http://pza.sanbi. org/salvia-namaensis.

Mcquillan, M., 2013, Salvia dolomitica, viewed 01 June 2018, from http://pza.sanbi. org/salvia-dolomitica. 
Muller, M., Schreiner, B., Smith, L., Van Koppen, B., Sally, H., Aliber, M. et al., 2009 Water security in South Africa, viewed 17 April 2019, from https://www.dbsa.org/ EN/AboutUs/Publications/Documents/DPD\%20No12.\%20Water\%20 security\%20in\%20South\%20Africa.pdf.

Narayani, M. \& Srivastava, S., 2018, 'Elicitation: A stimulation of stress in in vitro plant cell/tissue cultures for enhancement of secondary metabolite production, Phytochemistry Reviews 16(6), 1227-1252.

Ntobela, B., Akinpelu, E., Etsassala, N. \& Nchu, F., 2020, 'Effect of Beauveria bassiana on growth and bioactivities of Leek (Allium porrum)', in 18th SOUTH AFRICA Int' Conference on Agricultural, Chemical, Biological \& Environmental Sciences (ACBES-20), pp. 239-244, Johannesburg, November 16-17, 2020.

Ohashi, Y, Saneoka, H. \& Fujita, K., 2000, 'Effect of water stress on growth photosynthesis, and photoassimilate translocation in soybean and tropical pasture legume Siratro', Soil Science and Plant Nutrition 46(2), 417-425.

Osakabe, Y., Osakabe, K., Shinozaki, K. \& Tran, L., 2014, 'Response of plants to water stress', Frontiers in Plant Science 5(86), 1-8.

Pan, S., Zhou, S., Gao, S., Yu, Z., Zhang, S., Tang, M. et al., 2013, 'New perspectives on how to discover drugs from herbal medicines: CAM's outstanding contribution to modern therapeutics', Evidence-Based Complementary and Alternative Medicine 2013, 1-25. https://doi.org/10.1155/2013/627375

Prescott, C., Grayston, S., Helmisaari, H., Kaštovská, E., Körner, C., Lambers, H. et al., 2020, 'Surplus carbon drives allocation and plant-soil interactions', Trends in Ecology \& Evolution 35(12), 1110-1118.

Pusztahelyi, T., Holb, I. \& Pócsi, I., 2015, 'Secondary metabolites in fungus-plant interactions', Frontiers in Plant Science 573, 1-23. https://doi.org/10.1007/978-3 319-19456-1_39-1

Radácsi, P., Szabó, K., Szabó, D., Trócsányi, E. \& Németh-Zámbor, E., 2016, 'Effect of water deficit on yield and quality of lemon balm (Melissa officinalis L.)', Zemdirbyste-Agriculture 103(4), 385-390.

Rahimi, Y., Taleei, A. \& Ranjbar, M., 2017, 'Changes in the expression of key genes involved in the biosynthesis of menthol and menthofuran in Mentha piperita $L$ under drought stress', Acta Physiologiae Plantarum 39(203), 1-9.

Raimondo, D., 2015, South Africa's strategy for plant conservation, South African National Biodiversity Institute and the Botanical Society of South Africa, Pretoria, viewed 01 June 2018, from https://www.cbd.int/doc/world/za/za-nbsap-oth-en.pdf.

Ramakrishna, A. \& Ravishankar, G., 2011, 'Influence of abiotic stress signals on secondary metabolites in plants', Plant Signaling and Behavior 6(11), 1720-1731.

Ramos, M., Gordon, A., Minchin, F., Sprent, J. \& Parsons, R., 1999, 'Effect of water stress on nodule physiology and biochemistry of a drought tolerant cultivar of
common bean (Phaseolus vulgaris L.)', Annals of Botany 83(1), 57-63. https://doi. org/10.1006/anbo.1998.0792

Rejeb, I., Pastor, V. \& Mauch-Mani, B., 2014, 'Plant responses to simultaneous biotic and abiotic stress: Molecular mechanisms', Plants 3(4), 458-475.

Saha, D., Dasgupta, S. \& Saha, A., 2005, 'Anti-fungal activity of some plant extracts agains fungal pathogens of tea (Camellia sinensis)', Pharmaceutical Biology 43(1), 87-91.
Singh, A., Pandey, M. \& Singh, U., 2007, 'Anti-fungal activity of an alkaloid allosecurinine against some fungi', Mycobiology 35(2), 62-64.

Singleton, V., Orthofer, R. \& Lamuela-Raventos, R., 1999, 'Analysis of total phenols and other oxidation substrates and antioxidants by means of folin ciocalteu reagent', Methods in Enzymology 299, 152-178. https://doi.org/10.1016/ S0076-6879(99)99017-1

Srivastava, R., 2016, 'Now, farmers of drought-hit areas to grow medicinal, aromatic plants', Hindustan Times, viewed 01 June 2017, from https://www.pressreader. com/india/hindustan-times-lucknow/20160710/281672549273898.

Staden, L. \& Lotter, M., 2015, 'Important areas for plant diversity identified and incorporated into conservation processes', in D. Raimondo (ed.), South Africa's strategy for plant conservation, pp. 26-29. South African National Biodiversity Institute and the Botanical Society of South Africa, Pretoria.

Tátrai, Z., Sanoubar, R., Pluhár, Z., Mancarella, S., Orsini, F. \& Gianquinto, G., 2016 'Morphological and Physiological Plant Responses to Drought Stress in Thymus citriodorus', International Journal of Agronomy 2016, 1-8. https://doi. org/10.1155/2016/4165750

Umebese, C. \& Falana, F., 2013, 'Growth, phytochemicals and anti-fungal activity of Bryophyllum pinnatum L. subjected to water deficit stress', Africa Journal of Biotechnology 12(47), 6599-6604.

Umebese, C., Okunade, K. \& Orotope, O., 2012, 'Impact of water deficit stress on growth and alkaloid content of organs of Spigelia Anthelmia (L.)', Ife Journal of Science 14(2), 357-362.

Van Wyk, A. \& Prinsloo, G., 2018, 'Medicinal plant harvesting, sustainability and cultivation in South Africa', Biological Conservation 227, 335-342. https://doi. org/10.1016/j.biocon.2018.09.018

Wink, M., 2003, 'Evolution of secondary metabolites from an ecological and molecular phylogenetic perspective', Phytochemistry 64(1), 3-19. https://doi.org/10.1016/ S0031-9422(03)00300-5

World Economic Forum (WEF), 2017, Global risks of highest concern for doing business, viewed 15 May 2019, from http://reports.weforum.org/ globalrisks-2017/global-risks-of-highest-concern-fordoing-business-2017/.

World Resources Institute (WRI), 2015, Aqueduct projected water stress country rankings, viewed 15 May 2019, from https://goo.gl/o4UrqN.

W.W.F.-SA, 2016, Water: Facts \& futures, viewed 15 April 2019, from https://www. wwf.org.za/our_research/publications/?25181/Water-Facts-and-Futures.

Xu, B., Deng, X., Zhang, S. \& Shan, L. 2010, 'Biomass partition, leaf gas exchange and water relations of alfalfa and milkvetch seedlings in response to soil drying' Photosynthetica 48(4), 481-487.

Yuan, Y., Liu, Y., Wu, C., Chen, S., Wang, Z., Yang, Z. et al., 2012, 'Water deficit affected flavonoid accumulation by regulating hormone metabolism in Scutellaria baicalensis Georgi roots', PLoS One 7(10), 1-10. https://doi.org/10.1371/journal. pone.0042946 